Article

\title{
Electrochemical Impedance Characterization of Cell Growth on Reduced Graphene Oxide-Gold Nanoparticles Electrodeposited on Indium Tin Oxide Electrodes
}

\author{
Somasekhar R. Chinnadayyala ${ }^{1,+}+$ () Jinsoo Park ${ }^{2,+}{ }^{+}$Yonghyun Choi ${ }^{3}$, Jae-Hee Han ${ }^{4}$, \\ Ajay Kumar Yagati ${ }^{3}$ iD and Sungbo Cho ${ }^{2,5, *(D)}$ \\ 1 Department of Biomedical Engineering, Gachon University, Incheon 21936, Korea; ssreddy@gachon.ac.kr \\ 2 Gachon Advanced Institute for Health Science and Technology, Gachon University, Incheon 21999, Korea; \\ jspark88@gc.gachon.ac.kr \\ 3 School of Integrative Engineering, Chung-Ang University, Seoul 06974, Korea; \\ dydgus5057@gmail.com (Y.C.); ajay.yagati@gmail.com (A.K.Y.) \\ 4 Department of Energy IT, Gachon University, Seongnam 13120, Korea; jhhan388@gachon.ac.kr \\ 5 Department of Electronic Engineering, Gachon University, Seongnam 13120, Korea \\ * Correspondence: sbcho@gachon.ac.kr; Tel.: +82-31-750-5321 \\ + These authors contributed equally to this work.
}

Received: 13 December 2018; Accepted: 11 January 2019; Published: 17 January 2019

check for updates

\begin{abstract}
The improved binding ability of graphene-nanoparticle composites to proteins or molecules can be utilized to develop new cell-based assays. In this study, we fabricated reduced graphene oxide-gold nanoparticles (rGO-AuNP) electrodeposited onto a transparent indium tin oxide (ITO) electrode and investigated the feasibility of the electrochemical impedance monitoring of cell growth. The electrodeposition of rGO-AuNP on the ITO was optically and electrochemically characterized in comparison to bare, rGO-, and AuNP-deposited electrodes. The cell growth on the rGO-AuNP/ITO electrode was analyzed via electrochemical impedance measurement together with the microscopic observation of HEK293 cells transfected with a green fluorescent protein expression vector. The results showed that rGO-AuNP was biocompatible and induced an increase in cell adherence to the electrode when compared to the bare, AuNP-, or rGO-deposited ITO electrode. At $54 \mathrm{~h}$ cultivation, the average and standard deviation of the saturated normalized impedance magnitude of the rGO-AuNP/ITO electrode was $3.44 \pm 0.16$, while the value of the bare, AuNP-, and rGO-deposited ITO electrode was $2.48 \pm 0.15,2.61 \pm 0.18$, and $3.01 \pm 0.25$, respectively. The higher saturated value of the cell impedance indicates that the impedimetric cell-based assay has a broader measurement range. Thus, the rGO-AuNP/ITO electrode can be utilized for label-free and real-time impedimetric cell-based assays with wider dynamic range.
\end{abstract}

Keywords: cell-based assay; electrochemical impedance spectroscopy; electrodeposition; gold nanoparticle; graphene oxide

\section{Introduction}

Graphene-based nanomaterials have garnered much attention when it comes to sensors as they require enhanced measuring sensitivity and functionality due to their unique electrochemical, mechanical, and optical properties [1]. Using electrochemical measurements, graphene oxide (GO)-deposited electrode sensors have been used in the ultrasensitive detection of proteins and living microorganisms [2-4]. Graphene-nanoparticle-based hybrids have been developed to amplify 
the sensitivity and selectivity of the sandwich-type electrochemical immunosensor [5], the cell signaling-protein sensor [6], or apoptotic cell sensor [7]. The hybrid material of graphene anchored with nanoparticles gives rise to synergetic effects such as encouraging biocompatible conditions [8] or increasing the electrochemical sensing area of its tangled construction [9]. Moreover, the electrochemical measurement sensitivity of biomolecules was also shown to be reinforced by employing nanoparticles, which were deposited or patterned on the electrode surface by using electrodeposition or thermal deposition with evaporation masks [10-12]. Additionally, graphene-nanoparticle composites along with electrochemical measurement showed great potential, feasibility, and increased sensitivity for label-free and real-time biomolecular and protein detection due to its improved ability to capture analytes [13-15].

This improved binding ability of graphene nanocomposites to proteins can be utilized to develop new cytosensors for detecting target cells or cell-based assays for monitoring cell behavior. The cytosensor employing the graphene-nanomaterial composites showed high sensitivity and selectivity for sensing Du-145 cancer cells (limit of detection: 20 cells, linear range: $10^{2}$ to $10^{6}$ cells per $\mathrm{mL}$ ) [16] or HL-60 cells exposed to apoptotic inducer (limit of detection: 48 cells, measurement range: $10^{3}$ to $10^{7}$ cells per $\mathrm{mL}$ ) [7]. Cell-based assays using electrochemical impedance measurement have already been applied to non-destructively detect real-time cellular responses to drug candidates and disease risk factors [17]. Electrochemical impedance monitoring of cells on biocompatible gold or platinum electrodes has also been used in a wide range of applications, including wound healing assays, clinical diagnoses, cytotoxic assays, and drug development $[18,19]$. The transparent indium tin oxide (ITO) electrode made it possible to characterize the impedance of cells with better optical transmittance when compared to typical gold or platinum electrodes $[20,21]$. The surface of the ITO electrode could be modified via protein, peptide, or organic polymer coatings to achieve the biocompatibility [22-25] required for the impedance monitoring of cells. However, organic materials are easily affected by environmental factors including temperature, humidity, $\mathrm{pH}$, and solvent ions, and can be denatured such that substrate conditions cannot guarantee cell cultivation. Additionally, cell behavior is dependent on protein environments and the extracellular matrix.

In this study, we investigated the feasibility of a graphene nanoparticle (alternative to denaturable organic materials)-coated ITO electrode for the impedance characterization of cell growth. For this, an ITO microelectrode, deposited with reduced graphene oxide ( $\mathrm{rGO}$ ) and gold nanoparticles (AuNP), was prepared and characterized using electrochemical and optical analysis. The modified ITO electrode was then used for impedance measurements of HEK293 cells during cell growth to evaluate whether the rGO-AuNP could be used as biocompatible substrates for the impedance monitoring of cells. Furthermore, the measurement range of the cellular impedance measurement (the difference between the largest and smallest measurable value) using the highly-conductive rGO-AuNP-modified ITO electrode was compared to a bare ITO electrode to evaluate the enhancement of the hybrid sensor's performance.

\section{Materials and Methods}

\subsection{Fabrication of the ITO Electrode-Based Cultureware}

The ITO electrode, which was established in our previous studies [22,26], was prepared as shown in Figure 1. The brief fabrication process of the ITO electrode-based cultureware is as follows. The ITO film was deposited on a slide glass at a thickness of $450 \mathrm{~nm}$ via thermal evaporation and patterned via laser ablation to form sensing and counter electrodes, transmission lines, and terminal pads. The deposited ITO conductor had a sheet resistance of $4 \Omega$ /square. To insulate the transmission lines, a highly-resistive photoresist with a thickness of $2 \mu \mathrm{m}$ (SU-8 2002; MicroChem, Newton, MA, USA) was patterned on the ITO electrode via photolithography. The sensing electrode was circular with a radius of $250 \mu \mathrm{m}$ and separated by a distance of $2 \mathrm{~mm}$ from the relatively large counter electrode. 
Finally, the polystyrene chamber that holds cells and media was attached to the electrode using a silicone adhesive.
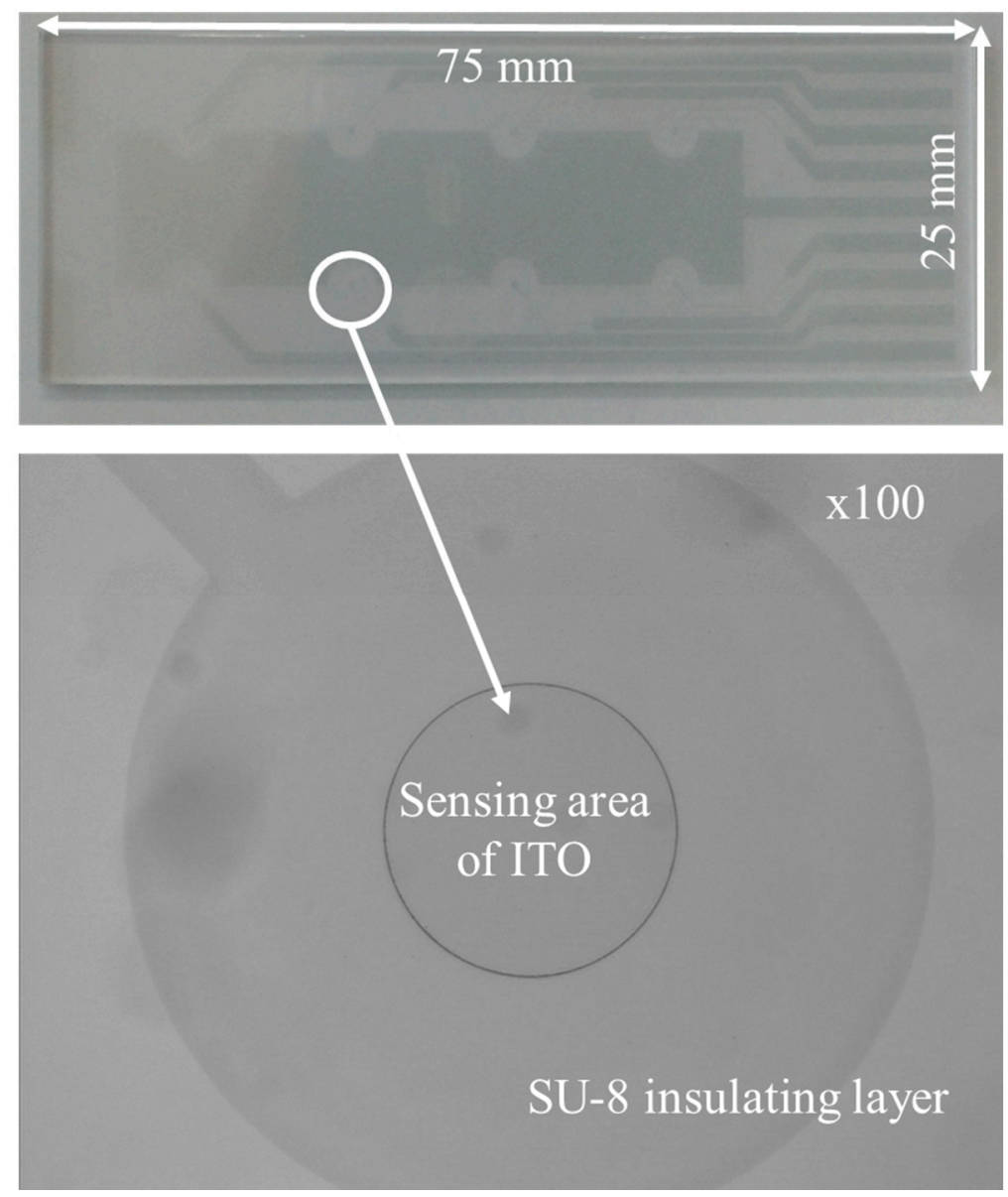

Figure 1. Fabricated indium tin oxide (ITO) electrode that has a circular working electrode with a radius of $250 \mu \mathrm{m}$ separated by a distance of $2 \mathrm{~mm}$ from the relatively large counter electrode.

\subsection{Electrochemical Deposition of $r G O-A u N P$ on the ITO Electrode}

$\mathrm{GO}$, gold(III) chloride trihydrate $\left(\mathrm{HAuCl}_{4} \cdot 3 \mathrm{H}_{2} \mathrm{O}\right)$, sodium phosphate monobasic anhydrous (purum p.a. $\geq 99.0 \%$, BioUltra), sodium phosphate dibasic anhydrous $(\geq 99.5 \%)$, and potassium ferrocyanide were obtained from Sigma Aldrich, St. Louis, MO, USA. GO $(1 \mathrm{mg} / \mathrm{mL})$ was diluted to prepare $0.5 \mathrm{mg} / \mathrm{mL}$ in $25 \mathrm{mM}$ sodium phosphate buffer ( $\mathrm{pH}$ adjusted to 5.4 ). $\mathrm{HAuCl}_{4} \cdot 3 \mathrm{H}_{2} \mathrm{O}$ was dissolved in deionized water $(18 \mathrm{M} \Omega \mathrm{cm})$ to a concentration of $0.5 \mathrm{mM}$.

For the electrodeposition of rGO and AuNP onto the ITO electrode surface, the established method [2,9] was employed. The potential applied on the ITO electrode using a potentiostat (CompactStat; Ivium, Eindhoven, The Netherlands) was $-1.4 \mathrm{~V}$ vs. $\mathrm{Ag} / \mathrm{AgCl}$ for $\mathrm{rGO}$ deposition and $-0.9 \mathrm{~V}$ vs. $\mathrm{Ag} / \mathrm{AgCl}$ for AuNP deposition. The rGO-AuNP composites were obtained by deposition using two-step chronoamperometry at $-1.4 \mathrm{~V}$ for $\mathrm{rGO}$ and at $-0.9 \mathrm{~V}$ for AuNP, respectively.

The optical properties of the ITO deposited by rGO and AuNP were characterized using a UV-Vis spectrophotometer (Optizen POP; Mecasys, Daejeon, Korea). Scanning electron microscopy (EM-30; COXEM, Deajeon, Korea) and transmission electron microscopy (Zeiss LEO 912 AB; Operating at a voltage of CM-200 kV) were used to determine the size and morphology of the decorated AuNPs in the hybrid nanocomposites deposited onto the ITO surface. 


\subsection{Impedance Measurement of Cells on the $r G O-A u N P / I T O$ Electrode}

The electrochemical impedance characteristics of the modified electrodes were analyzed to validate whether the electrode sensors were well fabricated. For this, the impedance spectra of the electrodes were measured with an electrolyte containing $10 \mathrm{mM}$ potassium ferricyanide $\mathrm{K}_{3}\left[\mathrm{Fe}(\mathrm{CN})_{6}\right]$ in $0.1 \mathrm{M}$ potassium chloride $(\mathrm{KCl})$ dissolved in deionized water in the frequency range of $0.1 \mathrm{~Hz}$ to $100 \mathrm{kHz}$ (CompactStat; Ivium, Eindhoven, The Netherlands).

HEK293 cells transfected with a green fluorescent protein expression vector (HEK293/GFP), Dulbecco's modified Eagle's medium (DMEM), fetal bovine serum (FBS), and penicillin-streptomycin (PS) were prepared for the experiments. HEK293/GFP cells $\left(2 \times 10^{5} / \mathrm{mL}\right)$ along with the culture medium (10\% FBS and 1\% PS in DMEM) were applied to the ITO electrode modified with rGO, AuNP, or rGO-AuNP. The viability and morphology of the cells cultured on each electrode were analyzed by fluorescent microscopy (XJF300T; UniNANO Technology, Yongin, Korea).

For the impedance monitoring of cells, the established experimental setup [22,26] was utilized, which consisted of the digital lock-in-amplifier (SR830; Stanford Research Systems, Sunnyvale, CA, USA), multiplexer, and LabVIEW program. The amplitude of the current flowing through the cells on the electrode was restricted to below $1 \mu \mathrm{A}$ to minimize electrical effects on the cells. The impedance spectra were measured in the frequency range of $10 \mathrm{~Hz}$ to $100 \mathrm{kHz}$ during cell cultivation.

\section{Results and Discussion}

\subsection{Characterization of the $r G O-A u N P / I T O$ Electrode}

GO is highly stable in water and can also be dispersed in an organic solvent due to the presence of oxygen functionalities. It is described as an insulator because of the disruption of its $\mathrm{sp}^{2}$ bonding networks and a hydroxyl group on or in its surface. However, when it is reduced (rGO), it exhibits a conductivity that can be used in sensor applications [27-29]. The current responses acquired during the electrochemical deposition of rGO and AuNP on the ITO electrode are shown in Figure 2a. The electrochemical reduction of GO can be expressed as follows [30]:

$$
\mathrm{GO}+a \mathrm{H}^{+}+b e^{-} \rightarrow r \mathrm{GO}+\mathrm{cH}_{2} \mathrm{O}
$$

The electrochemical deposition of AuNP determined by the reduction of $\mathrm{Au}^{3+}$ with $\mathrm{HAuCl}_{4}[31,32]$ can be expressed as follows:

$$
\mathrm{HAuCl}_{4}+3 \mathrm{H}^{+}+3 e^{-} \rightarrow \mathrm{Au}+4 \mathrm{HCl}
$$

The reductive current showed a significant increase during the first $10 \mathrm{~s}$ and $4 \mathrm{~s}$ for $\mathrm{rGO}$ and AuNP deposition respectively, and gradually reached a stationary value.

Figure $2 \mathrm{~b}$ shows the UV-Vis spectra of the rGO-, AuNP-, and rGO-AuNP-deposited ITO substrates using chronoamperometry. From the spectra of the rGO, a shoulder absorption at around $230 \mathrm{~nm}$ was caused by an $n-\pi^{*}$ transition shift of double bonded carbon-oxygen conjugation $(C=O$; electrons transition from a non-bonding (lone-pair) $\mathrm{n}$ orbital to an anti-bonding $\pi$ orbital called $\pi^{*}$ ). In the case of the AuNP, the absorption peak at about $550 \mathrm{~nm}$ was observed due to the resonance frequency in generating the surface plasmon. Therefore, the hybrid layer formation of rGO-AuNP was confirmed by the two UV-Vis absorption peaks at 224 233 $\mathrm{nm}$ for rGO and $548 \sim 557 \mathrm{~nm}$ for AuNP. 


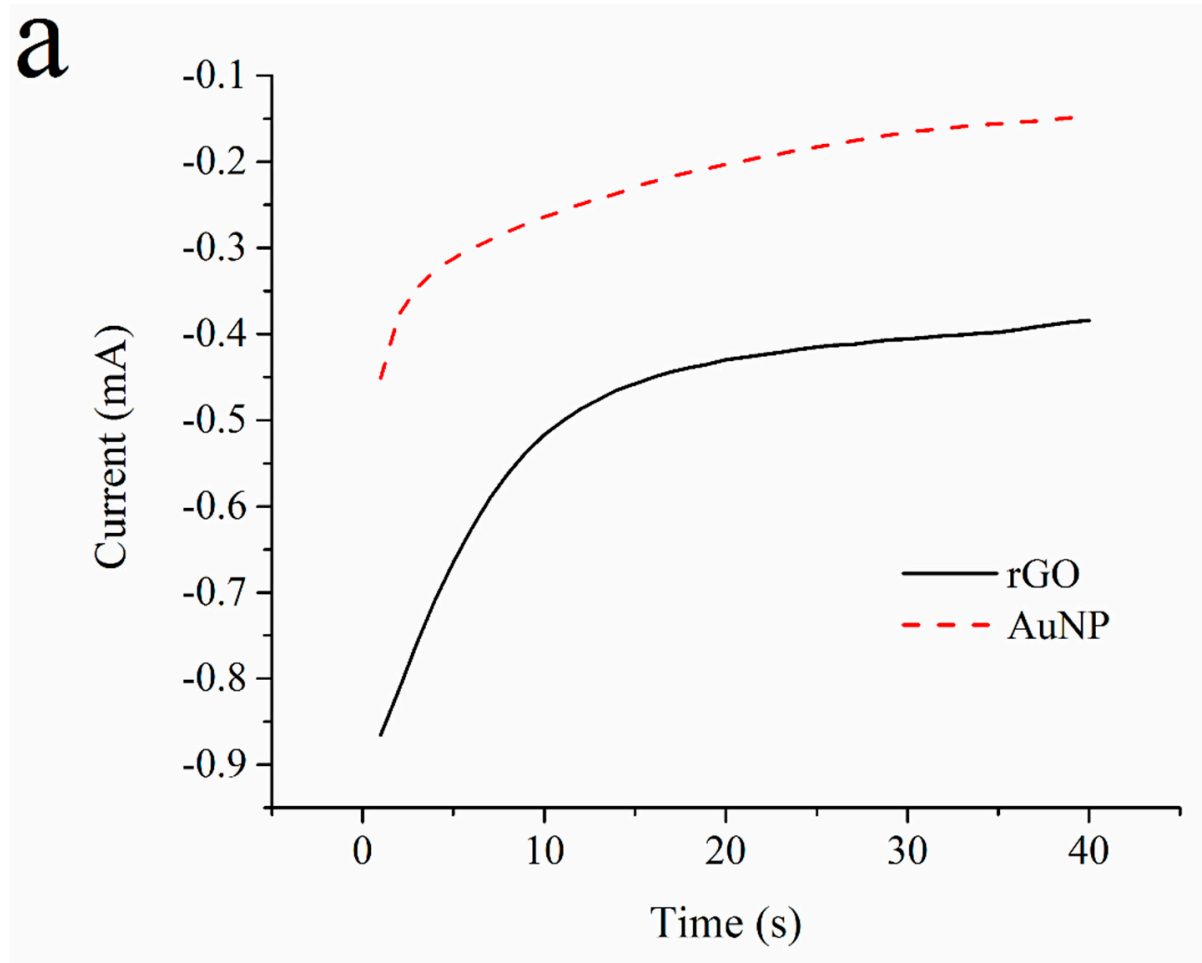

b

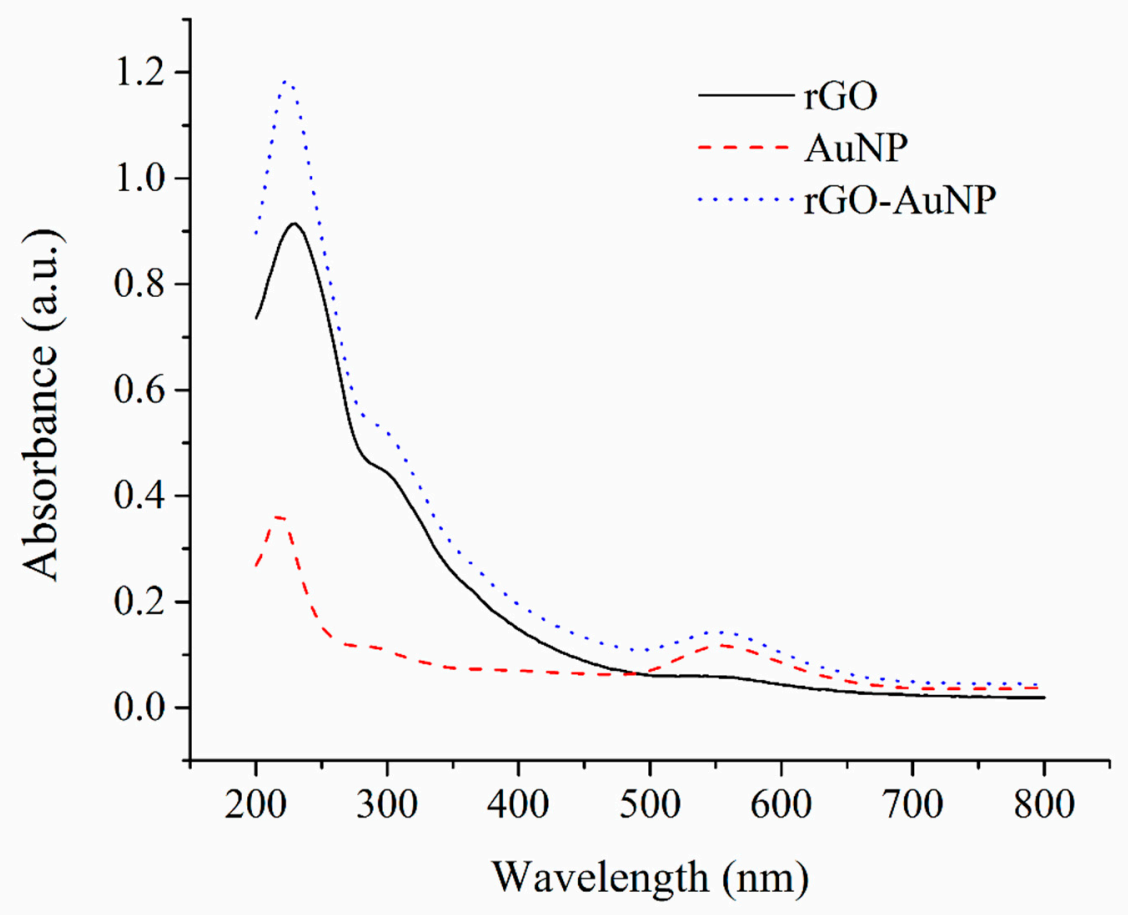

Figure 2. (a) Chronoamperograms measured during the electrochemical deposition of reduced graphene oxide (rGO) and gold nanoparticles (AuNP) on the ITO electrode at potentials of $-1.4 \mathrm{~V}$ and $-0.9 \mathrm{~V}$ vs. $\mathrm{Ag} / \mathrm{AgCl}$, respectively, (b) UV-Vis absorbance spectra of the rGO-, AuNP-, and rGO-AuNP-deposited ITO substrate using chronoamperometry.

The morphological features of rGO, AuNP and the rGO-AuNP nanocomposite were determined by transmission electron microscope (TEM) and scanning electron microscope (SEM) analysis. Figure 3 
shows characteristic TEM and SEM images of rGO, AuNP and the rGO-AuNP nanocomposite. rGO has a typical sheet-like structure. In contrast to rGO, the AuNPs exhibited spherical morphologies, evenly distributed with an average size of $15 \mathrm{~nm}$. In addition, the rGO-AuNP hybrid nanocomposite has AuNPs anchored to the surfaces of the rGO. The adhered particles also have spherical morphologies deposited with a diameter of $15 \mathrm{~nm}$ on the rGO surfaces. In the rGO-AuNP nanocomposite, the rGO looks like evenly-distributed silky waves of thin sheets, which may be significant in preventing the aggregation of rGO and upholding a surface, enabling the attachment of AuNP to the graphene sheets. The size and density of the AuNPs could be adjusted by controlling the chronoamperometric time, during which the AuNPs were formed by the nucleation and growth of Au deposition. Thus, it was found that the AuNPs were successfully deposited on the rGO/ITO to obtain the hybrid rGO-AuNP/ITO structure via chronoamperometry.
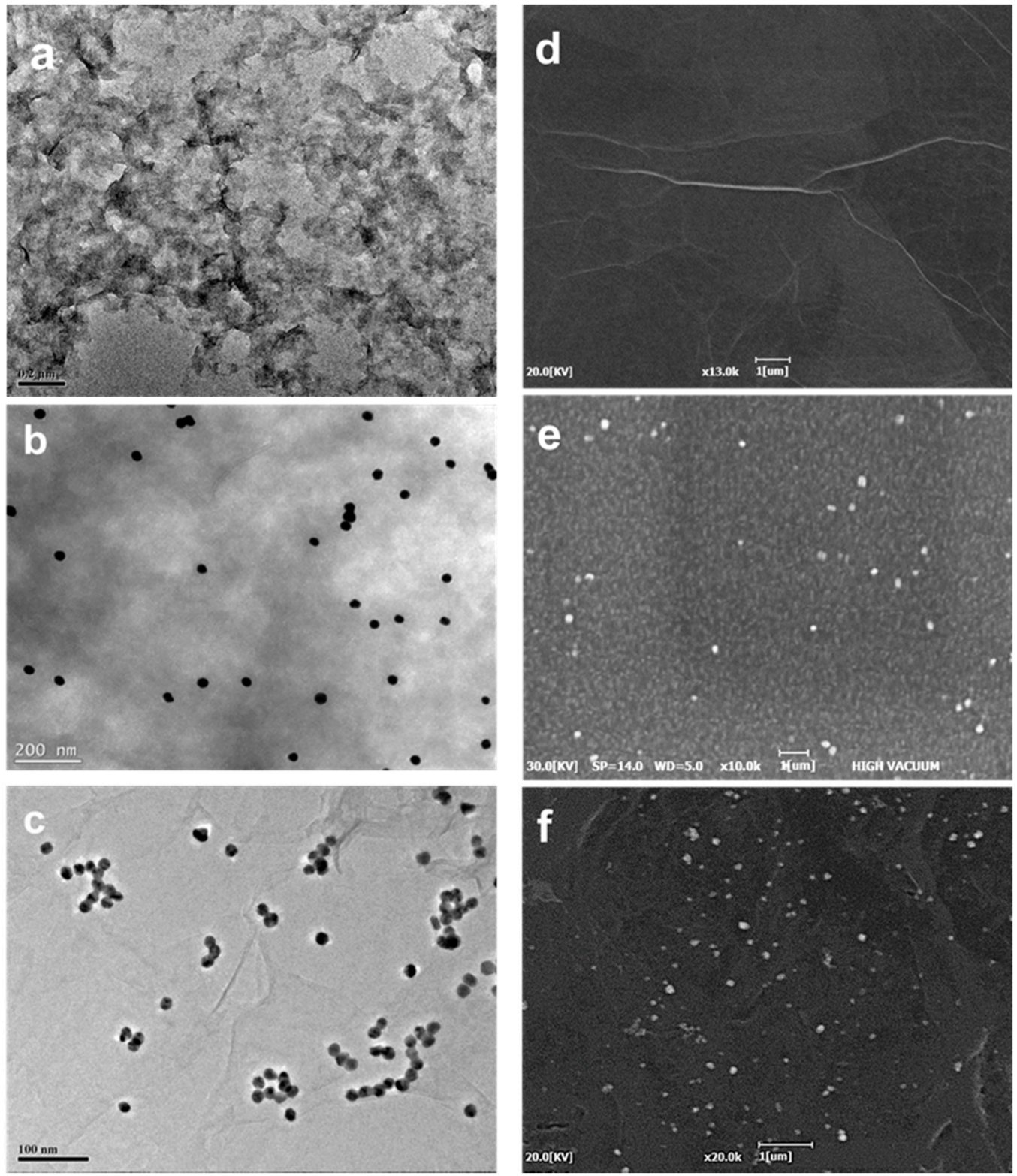

Figure 3. TEM (a-c) and SEM (d-f) image of the (a,d) rGO-, (b,e) AuNP-, and (c,f) rGO-AuNO-deposited ITO substrate using chronoamperometry. 


\subsection{Impedimetric Measurement of Cell Growth on the rGO-AuNP/ITO Electrode}

The measured electrochemical impedances of the bare ITO, AuNP/ITO, rGO/ITO, and rGO-AuNP/ITO in are shown in the Nyquist plot in Figure 4. The measured impedance data of the electrode $\left(Z_{E L}\right)$ are presented as symbols and analyzed via non-linear curve fitting using the following equation:

$$
Z_{E L}=\left(Z_{C P E} \cdot\left(R_{C T}+Z_{W}\right)\right) /\left(Z_{C P E}+R_{C T}+Z_{W}\right)+R_{S}
$$

where $Z_{C P E}$ is the constant phase element for the non-ideal capacitive characteristic of the electrode-electrolyte $\left(=T /(j \omega)^{P} ; j\right.$ is the imaginary unit, and $\omega$ is the angular frequency), $R_{C T}$ is the charge transfer resistance, $Z_{W}$ is the Warburg impedance, and $R_{S}$ is the solution resistance.

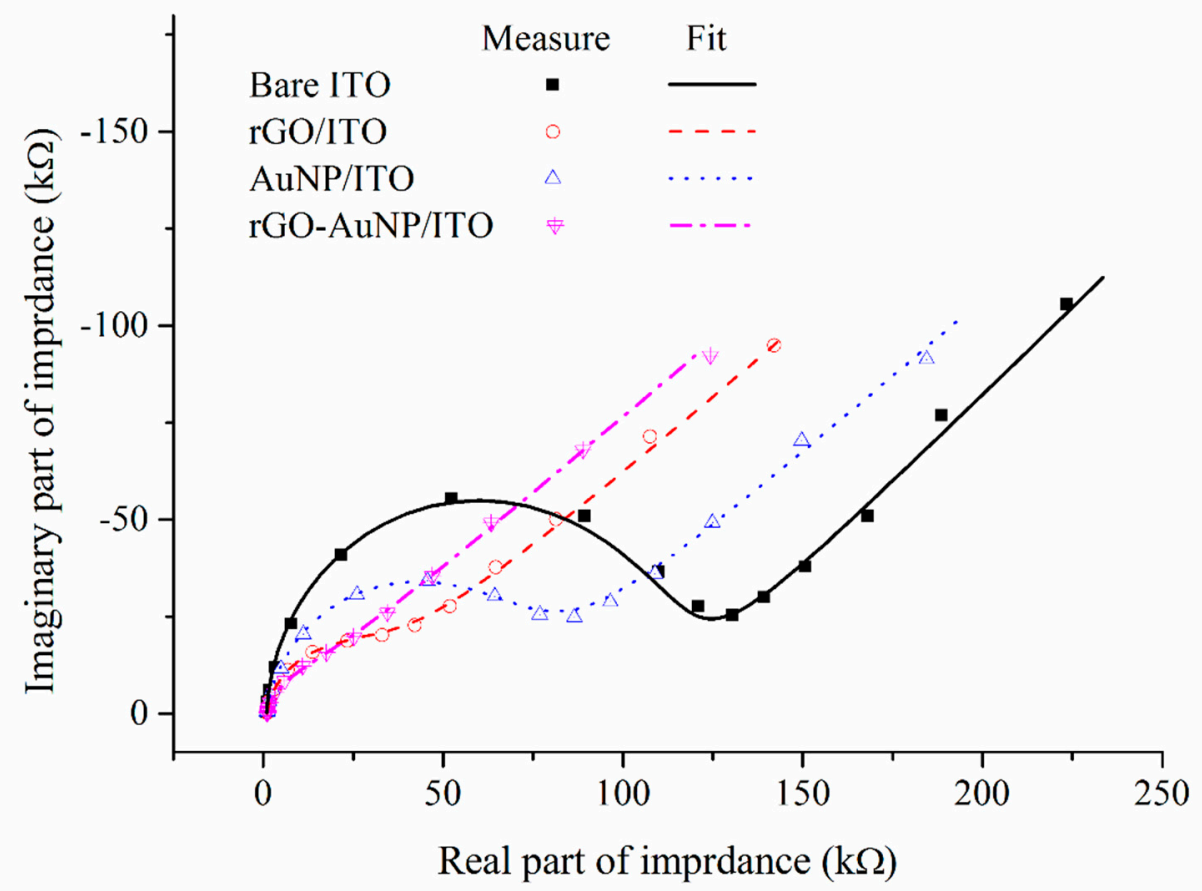

Figure 4. Impedance Nyquist plot of the bare, rGO-, AuNP-, and rGO-AuNP-deposited ITO electrodes measured with an electrolyte containing $10 \mathrm{mM} \mathrm{K}_{3} \mathrm{Fe}(\mathrm{CN})_{6}$ in $0.1 \mathrm{M} \mathrm{KCl}$ at a frequency of $0.1 \mathrm{~Hz}$ to $100 \mathrm{kHz}$ (measure) and curves (fit) fitted to the measured spectra via non-linear curve fitting using Equation (3).

The results showed that the measured impedance data of the electrode agreed with the fitted lines using Equation (3), and that the electrode interfacial impedance determining the faradaic and non-faradaic current was decreased by the electrochemical deposition of the electrode surface. In the parameters of Equation (3) extrapolated from the fitting analysis, $Z_{C P E}$ and $R_{C T}$ were selected to characterize the surface modification of the ITO electrode. The $Z_{C P E}$ values of the bare, AuNP-, rGO-, and rGO-AuNP-deposited ITO electrodes were found to be $90.05 /(j \omega)^{0.94}, 14.4 /(j \omega)^{0.88}, 4.71 /(j \omega)^{0.91}$, and $1.7 /(j \omega)^{0.88} \mathrm{M} \Omega$, respectively. The $R_{C T}$ values of the bare, AuNP-, rGO-, and rGO-AuNP-deposited ITO electrodes were found to be $118.07,77.59,34.67$, and $23.4 \mathrm{k} \Omega$, respectively. The decrease in the $P$ value of $Z_{C P E}$ of the AuNP- and rGO-AuNP-deposited electrodes can be explained by an increase in the surface roughness of the electrode caused by the electrochemical deposition process. The significant decreases in the $T$ value of $Z_{C P E}$ and $R_{C T}$ of the rGO-AuNP-deposited ITO electrode can be induced by an increase of the sensing area and charge transfer conductance of the modified electrode.

Figure 5a-c shows the fluorescent microscopic images of HEK293/GFP cells cultured for $40 \mathrm{~h}$ on bare, AuNP-, and rGO-AuNP-deposited ITO electrodes, when the cells were exposed to the blue light 
(400 490 nm). The average and standard deviation of the fluorescent intensity of the cells cultured on each electrode analyzed by ImageJ is shown in Figure 5d. The microscopic images proved that the rGO-AuNP deposited ITO electrode is biocompatible and that the optical density of the cells was observed to be higher on the rGO-AuNP deposited ITO electrode when compared to the bare, AuNP, or rGO-deposited ITO.
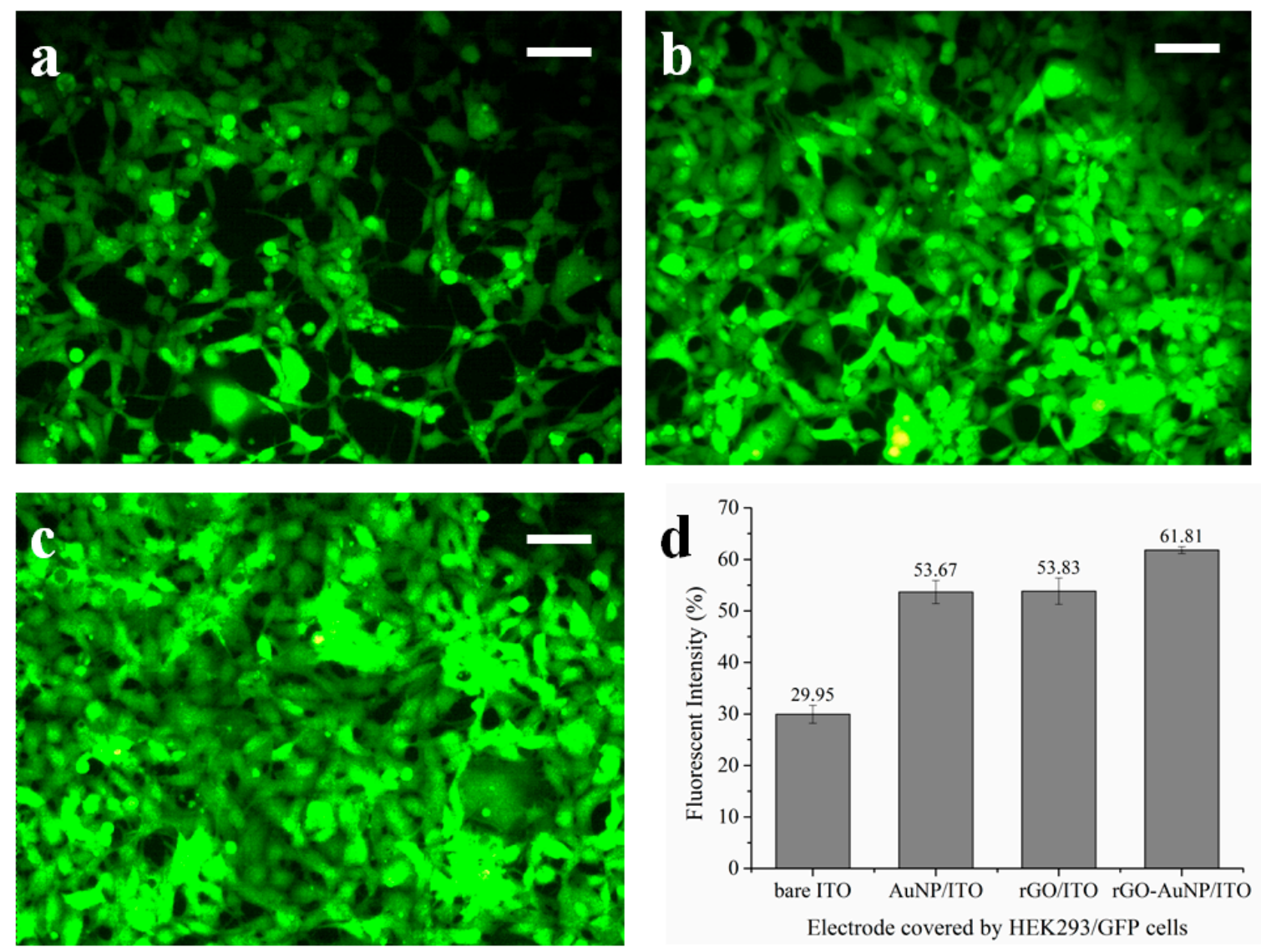

Figure 5. Fluorescent microscopic images of HEK293/GFP cells cultured for $40 \mathrm{~h}$ on (a) bare ITO, (b) AuNP/ITO, (c) rGO-AuNP/ITO (scale bar: $100 \mu \mathrm{m}$ ), and (d) fluorescent intensity of the cells on each electrode (column: Average, bar: Standard deviation, $n=4$ ).

The impedance magnitudes without or with HEK293/GFP cells cultured for $48 \mathrm{~h}$ on the bare or rGO-AuNP-deposited ITO electrode measured at a frequency of $10 \mathrm{~Hz}$ to $100 \mathrm{kHz}$ is shown in Figure 6a. The impedance magnitude of the electrode without cells showed the capacitive impedance of the electrode interface at low frequencies and the resistance of the culture media at high frequencies. As the cells adhered and proliferated on the electrodes during cell growth, an increase in the impedance magnitude at frequencies above $4.64 \mathrm{kHz}$ for the bare ITO or $215.4 \mathrm{~Hz}$ for rGO-AuNP-deposited ITO electrode was observed.

Figure $6 \mathrm{~b}$ demonstrates the normalized impedance magnitude at $21.5 \mathrm{kHz}$ recorded during cell culture on the bare, rGO-, AuNP-, and rGO-AuNP-deposited ITO electrodes. The normalized impedance magnitude $\left(\left.|Z|\right|_{n o r m}\right)$ of the HEK293/GFP cells was calculated as follows:

$$
|Z|_{\text {norm }}=|Z|_{\text {Cells }} /|Z|_{\text {No Cells }}
$$

where $|Z|_{\text {Cells }}$ and $|Z|_{\text {No Cells }}$ are the impedance magnitudes with and without cells, respectively. 


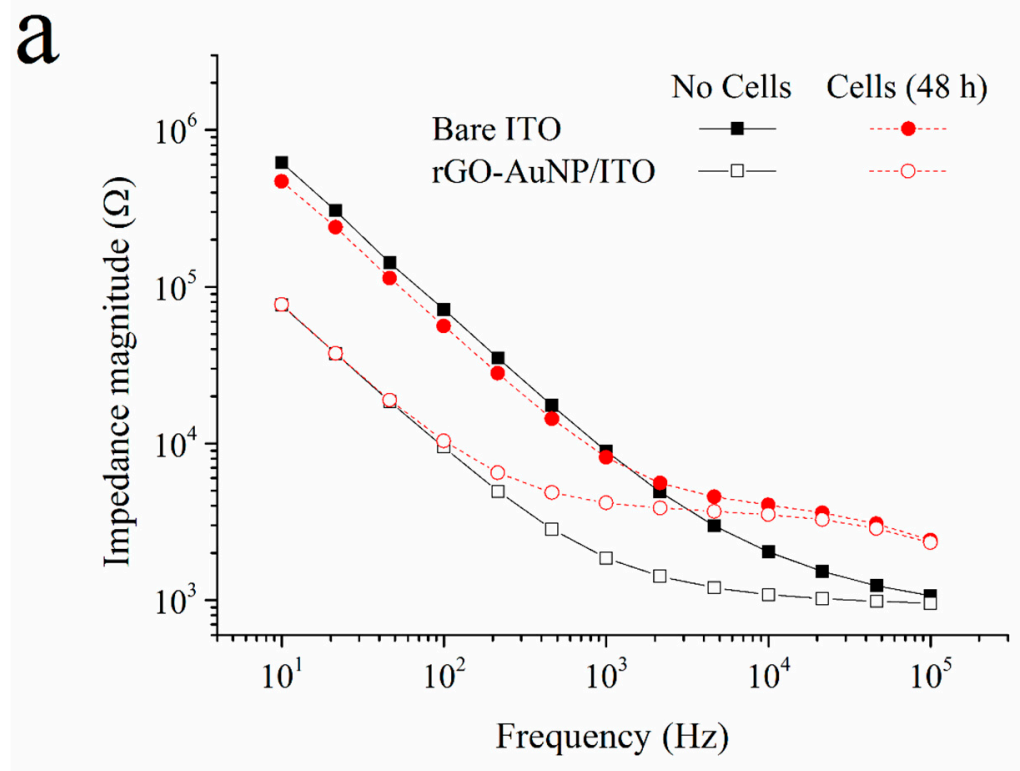

b

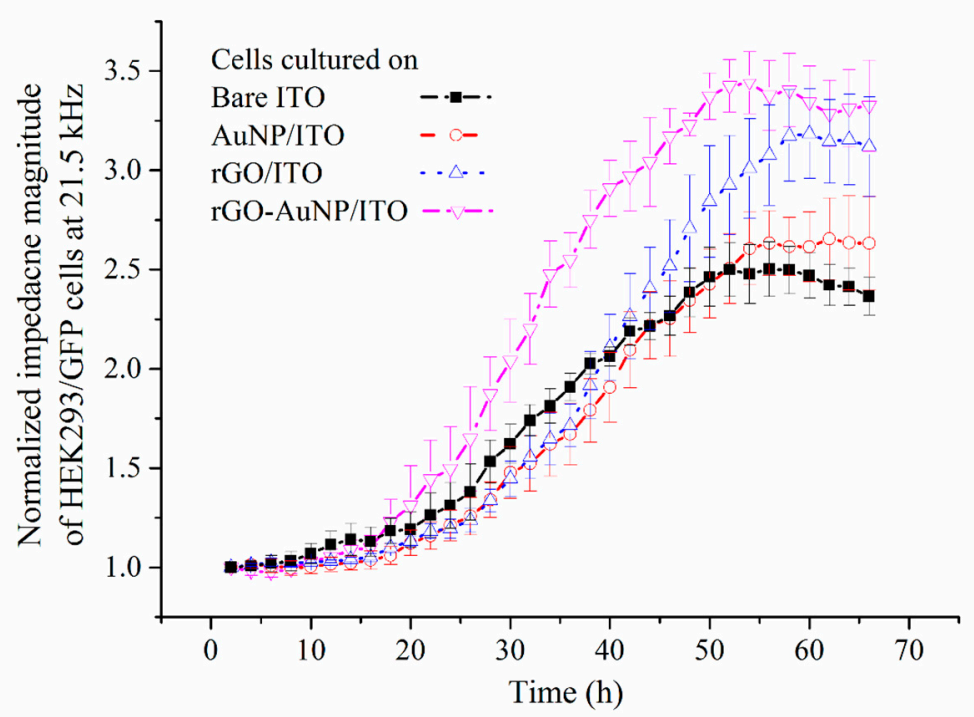

Figure 6. (a) Impedance magnitude without or with HEK293/GFP cells cultured for $48 \mathrm{~h}$ on the bare or rGO-AuNP-deposited ITO electrode with respect to frequency, (b) Normalized impedance magnitude at $21.5 \mathrm{kHz}$ measured during cell culture on the bare, AuNP-, rGO-, and rGO-AuNP-deposited ITO electrodes (symbol: average, bar: standard deviation, $n=4$ ).

The data are presented as averages (symbol) and standard deviation (bar) $(n=4)$. When the cells adhered to the electrode surface in the beginning of the cultivation $(<20 \mathrm{~h})$, the impedance values were weakly increased for all electrodes and a difference in values between each group of electrodes was not observed. However, the value of the cells on the rGO-AuNP/ITO electrode increased significantly when compared to the bare, rGO-, and AuNP-deposited ITO electrodes after $20 \mathrm{~h}$ of cultivation time dominated by cell proliferation. The normalized impedance magnitude of the cells then reached a saturation level $(>52 \mathrm{~h})$ when the cells proliferated sufficiently on the limited electrode surface. The saturated $|Z|_{\text {norm }}$ of the rGO-AuNP/ITO electrode was $3.44 \pm 0.16$ at $54 \mathrm{~h}$ cultivation, while the value of bare, AuNP-, and rGO-deposited ITO electrode was $2.48 \pm$ $0.15,2.61 \pm 0.18$, and $3.01 \pm 0.25$, respectively. The results indicated that the HEK293/GFP cells adhered and grew more efficiently on the rGO-AuNP-deposited ITO electrode when compared to the 
bare AuNP- or rGO-deposited ITO electrode. The higher saturated value of cell impedance makes it possible to implement the impedimetric cell-based assay with a broader measurement range. Thus, the rGO-AuNP-deposited ITO electrode can be utilized for label-free and real-time cell-screening assays with a wider dynamic range.

\section{Conclusions}

In this study, an rGO-AuNP-deposited ITO electrode was fabricated to be used as an advanced impedimetric cell sensor with a wider dynamic range. The hybrid structure of the rGO-AuNP was successfully deposited on the ITO electrode using chronoamperometry and characterized via UV-Vis spectroscopy, SEM, and impedance spectroscopy. Impedance monitoring of the cells via fluorescent microscopy proved that the rGO-AuNP/ITO electrode enhanced cell growth and yielded a higher cell density on the electrode surface. During the cell growth, the saturated normalized impedance magnitude of the rGO-AuNP/ITO electrode was higher (average and standard deviation: $3.44 \pm 0.16$ ) than the value of bare $(2.48 \pm 0.15)$, AuNP- $(2.61 \pm 0.18)$, or rGO-deposited (3.01 \pm 0.25$)$ ITO electrodes at $54 \mathrm{~h}$ cultivation. The higher saturated value of the cell impedance indicates that the impedimetric cell-based assay has a wider measurement range. Based on the results, the rGO-AuNP/ITO electrode can be utilized for advanced label-free and real-time impedimetric cell-based assays with broader dynamic range.

Author Contributions: Conceptualization, A.K.Y.; methodology, J.P.; validation, J.-H.H.; investigation, S.R.C.; writing - original draft preparation, Y.C.; project administration, S.C.

Acknowledgments: This research was supported by the National Research Foundation of Korea (grant No. 2017R1D1A1A09000712, 2018R1C1B6009385, and 2018M3A9F1023690).

Conflicts of Interest: The authors declare no conflict of interest.

\section{References}

1. Pumera, M. Graphene-based nanomaterials and their electrochemistry. Chem. Soc. Rev. 2010, 39, 4146-4157. [CrossRef] [PubMed]

2. Yagati, A.K.; Pyun, J.-C.; Min, J.; Cho, S. Label-free and direct detection of C-reactive protein using reduced graphene oxide-nanoparticle hybrid impedimetric sensor. Bioelectrochemistry 2016, 107, 37-44. [CrossRef] [PubMed]

3. Hernández, R.; Vallés, C.; Benito, A.M.; Maser, W.K.; Rius, F.X.; Riu, J. Graphene-based potentiometric biosensor for the immediate detection of living bacteria. Biosens. Bioelectron. 2014, 54, 553-557. [CrossRef] [PubMed]

4. Jang, H.D.; Kim, S.K.; Chang, H.; Roh, K.M.; Choi, J.W.; Huang, J. A glucose biosensor based on $\mathrm{TiO}_{2}$-Graphene composite. Biosens. Bioelectron. 2012, 38, 184-188. [CrossRef] [PubMed]

5. Liu, K.; Zhang, J.-J.; Wang, C.; Zhu, J.-J. Graphene-assisted dual amplification strategy for the fabrication of sensitive amperometric immunosensor. Biosens. Bioelectron. 2011, 26, 3627-3632. [CrossRef] [PubMed]

6. Zhang, J.-J.; Liu, Y.; Hu, L.-H.; Jiang, L.-P.; Zhu, J.-J. "Proof-of-principle" concept for ultrasensitive detection of cytokines based on the electrically heated carbon paste electrode. Chem. Commun. 2011, 47, 6551-6553. [CrossRef]

7. Zhang, J.-J.; Zheng, T.-T.; Cheng, F.-F.; Zhang, J.-R.; Zhu, J.-J. Toward the Early Evaluation of Therapeutic Effects: An Electrochemical Platform for Ultrasensitive Detection of Apoptotic Cells. Anal. Chem. 2011, 83, 7902-7909. [CrossRef]

8. Lee, W.C.; Lim, C.H.Y.X.; Shi, H.; Tang, L.A.L.; Wang, Y.; Lim, C.T. Origin of enhanced stem cell growth and differentiation on graphene and graphene oxide. ACS Nano 2011, 5, 7334-7341. [CrossRef]

9. Yagati, A.K.; Min, J.; Cho, S. Electrosynthesis of ERGO-NP Nanocomposite Films for Bioelectrocatalysis of Horseradish Peroxidase towards $\mathrm{H}_{2} \mathrm{O}_{2}$. J. Electrochem. Soc. 2014, 161, G133-G140. [CrossRef]

10. Chauhan, N.; Pundir, C.S. An amperometric acetylcholinesterase sensor based on $\mathrm{Fe}_{3} \mathrm{O}_{4}$ nanoparticle/ multi-walled carbon nanotube-modified ITO-coated glass plate for the detection of pesticides. Electrochim. Acta 2012, 67, 79-86. [CrossRef] 
11. El-Said, W.A.; Choi, J.W. Electrochemical Biosensor consisted of conducting polymer layer on gold nanodots patterned Indium Tin Oxide electrode for rapid and simultaneous determination of purine bases. Electrochim. Acta 2014, 123, 51-57. [CrossRef]

12. Golsheikh, A.M.; Huang, N.M.; Lim, H.N.; Zakaria, R.; Yin, C.Y. One-step electrodeposition synthesis of silver-nanoparticle-decorated graphene on indium-tin-oxide for enzymeless hydrogen peroxide detection. Carbon 2013, 62, 405-412. [CrossRef]

13. Yagati, A.K.; Choi, Y.; Park, J.; Choi, J.-W.; Jun, H.-S.; Cho, S. Silver nanoflower-reduced graphene oxide composite based micro-disk electrode for insulin detection in serum. Biosens. Bioelectron. 2016, 80, 307-314. [CrossRef]

14. Lin, M.; Pei, H.; Yang, F.; Fan, C.; Zuo, X. Applications of Gold Nanoparticles in the Detection and Identification of Infectious Diseases and Biothreats. Adv. Mater. 2013, 25, 3490-3496. [CrossRef] [PubMed]

15. Lee, Y.K.; Choi, J.; Wang, W.; Lee, S.; Nam, T.H.; Choi, W.S.; Kim, C.J.; Lee, J.K.; Kim, S.H.; Kang, S.S.; et al. Nullifying tumor efflux by prolonged endolysosome vesicles: Development of low dose anticancer-carbon nanotube drug. ACS Nano 2013, 7, 8484-8497. [CrossRef] [PubMed]

16. Yadegari, A.; Omidi, M.; Yazdian, F.; Zali, H.; Tayebi, L. An electrochemical cytosensor for ultrasensitive detection of cancer cells using modified graphene-gold nanostructures. RSC Adv. 2017, 7, 2365-2372. [CrossRef]

17. Sanghavi, B.J.; Wolfbeis, O.S.; Hirsch, T.; Swami, N.S. Nanomaterial-based electrochemical sensing of neurological drugs and neurotransmitters. Microchim. Acta 2015, 182, 1-41. [CrossRef] [PubMed]

18. Wang, L.; Hu, P.; Deng, X.; Wang, F.; Chen, Z. Fabrication of electrochemical NO sensor based on nanostructured film and its application in drug screening. Biosens. Bioelectron. 2013, 50, 57-61. [CrossRef] [PubMed]

19. Lee, S.; Jo, H.; Her, J.; Lee, H.Y.; Ban, C. Ultrasensitive electrochemical detection of engrailed-2 based on homeodomain-specific DNA probe recognition for the diagnosis of prostate cancer. Biosens. Bioelectron. 2015, 66, 32-38. [CrossRef] [PubMed]

20. Choi, Y.H.; Min, J.; Cho, S. Indium tin oxide based chip for optical and electrochemical characterization of protein-cell interaction. Jpn. J. Appl. Phys. 2015, 54,06FN03. [CrossRef]

21. Park, I.; Nguyen, T.; Park, J.; Yoo, A.Y.; Park, J.K.; Cho, S. Impedance Characterization of Chitosan Cytotoxicity to MCF-7 Breast Cancer Cells Using a Multidisc Indium Tin Oxide Microelectrode Array. J. Electrochem. Soc. 2018, 165, B55-B59. [CrossRef]

22. Park, I.; Hong, Y.; Jun, Y.-H.; Lee, G.-Y.; Jun, H.-S.; Pyun, J.-C.; Choi, J.-W.; Cho, S. Electrical Impedance Monitoring of C2C12 Myoblast Differentiation on an Indium Tin Oxide Electrode. Sensors 2016, 16, 2068. [CrossRef] [PubMed]

23. Bianchi, R.C.; Silva, E.R.; Antonia, L.H.D.; Ferrerira, F.F.; Alves, W.A. A Nonenzymatic Biosensor Based on Gold Electrodes Modified with Peptide Self-Assemblies for Detecting Ammonia and Urea Oxidation. Langmuir 2014, 30, 11464-11473. [CrossRef] [PubMed]

24. Zhao, H.; Zhu, B.; Luo, S.C.; Lin, H.A.; Nakao, A.; Yamashita, Y.; Yu, H. Controlled Protein Absorption and Cell Adhesion on Polymer-Brush-Grafted Poly(3,4-ethylenedioxythiophene) Films. Appl. Mater. Interfaces 2013, 5, 4536-4543. [CrossRef]

25. Kafi, M.A.; El-Said, W.A.; Kim, T.H.; Choi, J.W. Cell adhesion, spreading, and proliferation on surface functionalized with RGD nanopillar arrays. Biomaterials 2012, 33, 731-739. [CrossRef] [PubMed]

26. Jun, H.S.; Dao, L.T.M.; Pyun, J.C.; Cho, S. Effect of cell senescence on the impedance measurement of adipose tissue-derived stem cells. Enzym. Microb. Technol. 2013, 53, 302-306. [CrossRef] [PubMed]

27. Srivastava, S.; Kumar, V.; Ali, M.A.; Solanki, P.R.; Srivastava, A.; Sumana, G.; Saxena, P.S.; Joshi, A.G.; Malhotra, B.D. Electrophoretically deposited reduced graphene oxide platform for food toxin detection. Nanoscale 2013, 5, 3043-3051. [CrossRef]

28. Narváez, E.M.; Merkoçi, A. Graphene Oxide as an Optical Biosensing Platform. Adv. Mater. 2012, 24, 3298-3308. [CrossRef]

29. Joshi, R.K.; Carbone, P.; Wang, F.C.; Kravets, V.G.; Su, Y.; Grigorieva, I.V.; Wu, H.A.; Geim, A.K.; Nair, R.R. Precise and Ultrafast Molecular Sieving Through Graphene Oxide Membranes. Science 2014, 343, 752-754. [CrossRef]

30. Dreyer, D.R.; Park, S.; Bielawski, C.W.; Ruoff, R.S. The chemistry of graphene oxide. Chem. Soc. Rev. 2010, 39, 228-240. [CrossRef] 
31. Rathod, D.; Warren, S.; Keane, K.; Egan, D.A.; Dempsey, E. Evaluation of a modified carbon micromesh electrodeas a new substrate for electrochemical immunosensing. Anal. Methods 2011, 3, 799-805. [CrossRef]

32. Guin, S.K.; Pillai, J.S.; Ambolikar, A.S.; Saha, A.; Aggarwal, S.K. Template-free electrosynthesis of gold nanoparticles of controlled size dispersion for the determination of lead at ultratrace levels. RSC Adv. 2013, 3, 17977-17988. [CrossRef] 